Abeygunawardena and Barba. 2000. Sri Lankan Journal of Agricultural Economics. Volume 3, Number 1.Pp 71 - 92.

\title{
Emission Trading as a Tool for Environmental Management
}

\section{P. Abeygunawardena* and Ricardo Barba ${ }^{* *}$}

\begin{abstract}
Although there is continuing progress in the use of ET for environmental management, there is no clear direction that one can establish in terms of its future. Directional change occurs as different models are implemented and evaluated under changing technological and cultural circumstances. If the emphasis will be on international emission trading or CDM, a thorough review of past Joint Implementation efforts should be undertaken. There is no doubt that lessons gained can shape up the trading system. If the focus is to be on domestic trading of selected emissions, then capacity building and further pilot trading should be pursued. The promotion of ET for environmental management is consistent with the broad development strategies adopted by many developing countries in protecting the environment. It is important that the governments provide policy support through studies that assess experiences in ET and identify the positive and negative aspects of implementation, and assist in capacity building in terms of training programs, human resource development, and institutional strengthening. It is also important to promote regional cooperation by exploring potential for CDM and related activities of various international protocols.
\end{abstract}

\section{Introduction}

Emission trading (ET) is a market-based policy tool, which can be used for environmental management. ET refers to the ability of sources of pollution to buy or sell the rights to release emissions. Buying and selling these rights will allow sources to achieve compliance with legal obligations and meet a regulatory standard. Market-based instruments (MBIs), including ET, have a number of advantages over traditional regulatory methods. MBIs give those responsible for creating pollution an

\footnotetext{
* Senior Economist, Energy Division (East), Asian Development Bank, Manila, Philippines.

** Independent Consultant.
} 
incentive to reduce pollution below permitted amounts when it is relatively inexpensive to do so. That feature, in turn, provides motivation for sources to become more efficient with regard to pollution control options and costs. Technological improvement and innovation are stimulated, resulting in greater opportunities to reduce pollution at lower cost. The more widely dispersed and smaller the sources, the more difficult it is to rely on traditional methods such as source-specific limits, inspections, and enforcement. MBIs harness forces of the market to give all sources, large and small, the motivation to find lower costs of limiting pollution.

This paper puts the rationale of MBIs particularly ET into perspective and discusses selected institutional, policy and economic aspects. ET as an environmental management tool is discussed thorough a review of experiences worldwide ${ }^{1}$. This review can form a basis for its potential use in developing countries.

\section{The Rationale for using ET and Other MBIs}

Pollution, the by-product of an output, is created outside normal market transactions. Though it has little or no cost to the source, it imposes cost on others and damages valuable environmental assets of a society. One way to control pollution is to rely on private negotiations between those who bear the costs of pollution and the source of pollution. Under the assumption of costless transactions between sources of pollution and those harmed by pollution, such negotiations can lead to an optimal/economically efficient level of pollution control (Coase, 1960). The assumption of costless transactions, which are necessary for those affected by pollution to negotiate successfully with sources, is seldom realistic. The transaction costs are likely to be higher the more people affected and the more they are geographically dispersed.

Negotiations between those affected and sources of pollution is not usually a reliable means of control. Thus, environmental legislation provides other mechanisms for internalizing pollution externalities. In one approach the pollution control authority specifies, in considerable detail, requirements for different source categories. The regulations may impose discharge limits or much more, such as the technology that must be used, the inputs that must be used, or characteristics of outputs that are produced. This regulatory approach is called command and control (CAC) approach. This 
contrasts with market-based or incentive approaches, which offer

1. Experiences in ET are condensed from Appendix A of the ADB publication Emissions Trading in the Energy Sector: Opportunities for the People's Republic of China.

financial and other related incentives agency could issue directives to each to reduce pollution. An incentive based regulatory strategy gives sources flexibility in selecting both the type and magnitude of response.

The figure 1 depicts the incremental damage of increased levels of pollution and the incremental costs of controlling pollution. The economically efficient level of control limits pollution to $\mathrm{E}_{1}$. Up to that level of pollution, the incremental damage from successive units of pollution is less than the incremental costs of control. Beyond $\mathrm{E}_{1}$, incremental damage exceeds incremental control cost. Net benefits of pollution control are maximized at $\mathrm{E}_{1}$.

Pollution should be managed so that only $E_{1}$ units are released to the environment. The pollution control source so that total emission equals $\mathrm{E}_{1}$. Whether the directives could be given to minimize costs, as portrayed in the diagram, is an open question. Economic instruments provide another alternative. A charge equal to $\mathrm{C}_{1}$ could be imposed on each unit of pollution. This would require knowledge of marginal abatement costs and marginal damage in order to determine the correct charge. A third approach is to cap total emissions at $\mathrm{E}_{1}$ and allow trading of emission allowances among the various sources.

Several factors will affect the relative economic efficiency of these different approaches to environmental management (that is, how close one gets to $\left.\mathrm{E}_{1}, \mathrm{C}_{1}\right)$. Consider, first, the sources of

Figure 1: $\quad$ Optimum net benefits from pollution control.

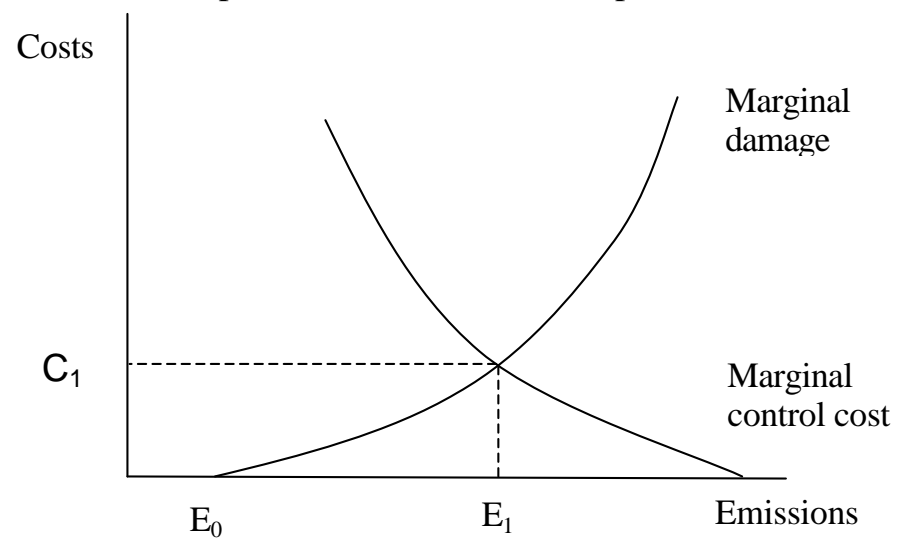


pollution. Are the costs of control known with certainty? If not, how great is the uncertainty? Is the technology of pollution control static, or is it likely to change over time? Can the quantity of pollution from each source be measured (or approximated) easily? How many sources are there for each pollutant? Are incremental control costs similar for different sources, or do costs exhibit considerable variation? On the damage side, does a unit of pollution from each source have the same impact on health and the environment, regardless of where it is released? Are the impacts on health and the environment known with certainty? If not, how great is the uncertainty? At which juncture do major uncertainties arise: imprecise knowledge of the effect of pollution on environmental quality, exposures, physical effects, or economic valuation of effects? How many parties are experiencing pollution damage? Is it critical to control pollution within narrow limits to achieve environmental goals, or are damage functions such that there is a continuum of effects from less serious to more serious, with no obvious unacceptable level of pollution?

Depending on these parameters, some tools of environmental management are likely to perform better than others. Performance can be measured in various ways. While economists would place the emphasis on economic efficiency, other criteria such as fairness, political acceptability, stimulus for innovation and technical improvement, enforceability, raising revenue, and consistency with religious and moral precepts could also be used in place of efficiency. Cost-effectiveness is a compromise criterion that takes both economics and the political and legal structure into account by finding the least cost means of achieving a stated environmental goal. This criterion is often used to identify least cost pollution control measures to achieve a given environmental objectives.

MBIs, which include pollution and natural resource taxes and charges, deposit-refund systems, tradable emission rights, performance bonds, and other instruments, take advantage of the fact that different firms, industries, and sectors typically face different marginal control costs for the environmental damage they generate. The least expensive way to achieve a specified level of pollution reduction is therefore to permit different polluters to abate different amounts of pollution (with the low-cost abators reducing more and the highcost abators reducing less). MBIs allow polluters to make their own 
decisions about how much to abate, in response to policy measures that alter the cost of polluting. If properly designed, these policy measures set the incremental cost of pollution abatement to the source equal to the cost of the incremental environmental damage to society. Under such a system, progress toward environmental goals is both efficient and cost-effective (ADB, 1997).

Theory and practice tell us that MBIs have at least three advantages over traditional forms of regulation: Static Efficiency (or "cheaper now") - Allowing firms the flexibility to make decisions based on the costs of abatement, will lower the aggregate costs of compliance. A given pollution target can be met at overall lower cost than with traditional regulations. Dynamic Efficiency ("or cheaper in the future") - MBIs can provide a continuous incentive for environmental improvement and process changes in the medium term, because every positive emission has a price attached to it. Revenue raising: the use of MBIs for environmental management can raise money. A charge for instance, generates funds that can be used to finance environmental clean up or replace existing taxes. There are distributional aspects one has to consider in environmental policy making.
Although use of MBIs in Asia remains quite modest, experience is growing. Examples include effluent charges on wastewater; $\mathrm{SO}_{2}$ charges, differential pricing for unleaded petrol; and deposit refund systems to promote material recycling. The People's Republic of China, Singapore, South Korea, Malaysia; Taipei, China, Philippines, Indonesia, and Thailand, have all adopted the polluter pays principle in one form or another. South Asian countries also have changed their attitude towards MBIs and some are already in place for environmental management. It is interesting to note that there is a similar trend or correlation between degree of openness of an economy or market orientation for general economic activities, with the level of use of MBIs for environmental management in that country. Further, interesting pilot programs are being initiated to test the more innovative MBIs such as tradable permits for air and water quality. So far, much of the emphasis has been on the brown sector, rather than on natural resource management. However, this too is changing, and performance bonds for forestry as transferable development rights for coastal resources are being experimented with. 
It has been realised more often than not that the objective of a MBI is not to ensure zero environmental damage but a reasonable level of reduction. The comparison between the benefits and costs of achieving higher environmental standards is indisputable in discussing any possible changes to the system of environmental management. This allows a country to select an environmental system which promises to achieve certain environmental outcomes at a lower cost than costlier alternatives. It implies that a policy that could identify areas of environmental concerns where more benefits can be obtained from a unit of pollution abatement cost will be favored by the countries.

\section{Pre-cursors of ET in Asia}

\section{The Case of the People's Republic of China}

In most cities of Asia, ambient pollution levels are unacceptably high for key air pollutants such as $\mathrm{SO}_{2}$ and total suspended particulates. Scarce water resources are polluted throughout much of the region. Very large pollution reductions will be required to reduce pollution concentrations to acceptable levels while maintaining economic growth at the desired rate. The large reductions required, coupled with the fact that marginal costs of controlling emissions of the same pollutant vary across source categories, led to an investigation of ET as a means of reducing costs of compliance with acceptable standards. These trading often will be limited to a single country or a specific location of the country. Such trading can be referred to as domestic emission trading.

Asian countries such as the People's Republic of China (PRC) have addressed their environmental problems through the formulation, implementation, and enforcement of environmental regulations. Many of these regulations are relevant to ET. The 1995 revised Law on Control of Air Pollution requires the establishment of national acid rain control zones and $\mathrm{SO}_{2}$ pollution control zones. With respect to $\mathrm{SO}_{2}$ emissions, the PRC Government requires stricter enforcement of regulations and standards. Since 1996, total amount control (TAC) pollution programs have become enforceable nationwide. In January 1998, the State Council approved the National Acid Rain and $\mathrm{SO}_{2}$ Pollution Control Zoning Plan in accordance with the Law on Control of Air Pollution. The control zones for both $\mathrm{SO}_{2}$ and acid rain cover about 11 per cent of the country's total land area. The TAC Plan, which was prepared by the State 
Environmental Protection Administration, is designed to limit $\mathrm{SO}_{2}$ emissions to 24.6 million tons by 2010, that is the 1995 level. These reductions represent substantial changes relative to business-as-usual and will require large pollution abatement investments amounting to the equivalent of about $\$ 9$ billion per year by 2010 .

The large reductions in emissions needed under the TAC program are unlikely to be achieved through the existing Pollution Levy System (PLS). The current PLS imposes a fee only on releases of pollution in excess of what is permitted. Except for $\mathrm{SO}_{2}$, which is charged Y 0.2 for every kilogram released, releases within permitted amounts are free. This provides little incentive to seek cost-effective reductions below permitted amounts. To accomplish the very large reductions in emissions envisioned with TAC, reductions below permitted amounts will be required at many sources. A major revision of the PLS that charges rates higher than abatement cost for all emissions could achieve the desired result. A tax on the sulfur content of coal, while simpler to monitor, could also achieve the desired outcome, though likely at a higher cost. It reduces choices because it gives no credit for coal users who control emissions at or after combustion.
The fact that marginal abatement costs vary significantly across source categories creates a situation in which there is a potential for significant gains from trading pollution reduction obligations. Electric power and district heating systems are by far the largest sources of $\mathrm{SO}_{2}$ emissions, and they also have the lowest incremental pollution control costs. Allowing the trading of pollution control obligations across sources would lead to greater control by low-cost sources and less control by high-cost sources. All sources would benefit from a lower total control cost burden. The PRC has pilot-tested several emission-offset trades. These trades have resulted in cost savings and environmental improvement. They demonstrate that when faced with a strict limit on emissions, sources find ways to reduce emissions elsewhere. However, since many facilities are state-owned enterprises, and because many of the factor and output markets are not free of controls, estimation of historic as well as potential future cost savings is difficult.

Incremental electricity production through new coal-fired power plants will result in changes in overall emissions of several pollutants, including particulates, $\mathrm{SO}_{2}$, nitrogen oxides $\left(\mathrm{NO}_{\mathrm{X}}\right)$, and carbon dioxide $\left(\mathrm{CO}_{2}\right)$, and there will 


\begin{tabular}{|c|c|}
\hline \multicolumn{2}{|c|}{ Design Elements of Emissions Trading System } \\
\hline Sources included & All sources or just large industrial sources? \\
\hline What is traded & $\begin{array}{l}\text { Allowances for future pollution or credits for past } \\
\text { Control efforts? }\end{array}$ \\
\hline Legal status & $\begin{array}{l}\text { Do allowances or credits have status as property } \\
\text { rights? }\end{array}$ \\
\hline Which pollutant(s) & : For example, $\mathrm{SO}_{2}$ as well as particulates? \\
\hline Region & : Local for $\mathrm{SO}_{2}$, regional for acid rain? \\
\hline New sources & : How do they obtain pollution permits? \\
\hline Pollution limits & $\begin{array}{l}\text { : To achieve total amount control (TAC) goals for } \\
\text { each year? }\end{array}$ \\
\hline Allocating rights & : Grandfather, auction or some other mechanism? \\
\hline Who can trade & $\begin{array}{l}\text { Only affected sources or brokers, NGOs, and } \\
\text { others? }\end{array}$ \\
\hline Trading & $\begin{array}{l}\text { Only existing allowances/credits or } \\
\text { supplementary amounts too? }\end{array}$ \\
\hline Monitoring & $\begin{array}{l}\text { Continuous emission monitors or another, less- } \\
\text { costly method? }\end{array}$ \\
\hline Enforcement & $\begin{array}{l}\text { Who has responsibility for reporting and who has } \\
\text { oversight? }\end{array}$ \\
\hline Noncompliance & $\begin{array}{l}\text { : What penalties will be imposed for } \\
\text { noncompliance? }\end{array}$ \\
\hline Transparency & $\begin{array}{l}\text { Will full accounting of system be made available } \\
\text { to public? }\end{array}$ \\
\hline
\end{tabular}

be a need to offset those increases with decreases elsewhere due to the limitations imposed by the TAC program. Credits for particulates, $\mathrm{SO}_{2}$, and $\mathrm{NO}_{\mathrm{X}}$ reductions can be traded under existing pilot programs or sold in more expanded marketable permit programs within the PRC.

\section{Experiences in Implementing ET}

Emissions trading for environmental management has been successfully applied in several countries, most notably the US. The following examples are described to understand the mechanics of implementing ET, and establish the possible directions ET may take insofar as environmental management is concerned.

\section{US Experience}

\section{US Acid Rain Program}

In Title IV of the Clean Air Act Amendments of 1990, the US 
Congress created a program to cut total national $\mathrm{SO}_{2}$ emissions by approximately 50 per cent at an estimated cost of about $\$ 5$ billion per year. At that time, quantifiable economic benefits were believed to be in the range of $\$ 1$ billion per year (Portney, 1990). The program set a cap of 8.95 million tons of $\mathrm{SO}_{2}$ per year, to be achieved in two phases. During Phase I, which runs from 1995 through 1999 , the 110 highest emitting coal-fired power plants (with a total of 263 coal-burning units) must reduce emissions to satisfy a tonnage cap. These socalled "Table A" units were targeted for the first phase because their emissions exceeded 2.5 pounds of $\mathrm{SO}_{2}$ per million Btu and their capacity exceeded 100 megawatts (MW). Phase I will yield a nationwide reduction in emissions of approximately 3.5 million tons of $\mathrm{SO}_{2}$. In the second phase, which begins in 2000, all power plants producing more than $25 \mathrm{MW}$ and all new facilities must meet a lower emission cap. Phase II reductions will total an additional 5 million tons and will reach the overall 8.95 million-ton cap.

In March 1995, USEPA expanded the acid rain program to include industrial facilities that burn fossil fuels (USEPA, 1995). The rule establishes an "opt-in" program that allows industrial and other sources to participate in the existing $\mathrm{SO}_{2}$ program that previously included only utilities. Industrial sources that participate in the program will have an allocation of allowances that they can use for compliance, sell or trade to other sources. These provisions allowing industrial sources to opt-in were little used because of high transactions costs (Atkeson, 1997). Title IV also sets allowable limits on $\mathrm{NO}_{\mathrm{X}}$ emissions from utility boilers. An owner of two or more power plants may comply with the $\mathrm{NO}_{\mathrm{X}}$ requirement by averaging emissions across all its power plants, a rudimentary form of ET.

At the end of each quarter, USEPA receives more than 1,700 reports containing hourly emissions data for affected units. More than 90 per cent of this data is received electronically. Using these data and the allowance record for each unit, USEPA tracks compliance. Across the industry, 1995 emissions measured with continuous emission monitoring (CEM) systems averaged 7 per cent higher than emissions calculated with formulas based on technology and fuel use that had been used to determine compliance with environmental regulations. Under the authority of Title IV, USEPA developed an allowance tracking system that serves as the official record of ownership and transfers. The system currently 
requires a paper form that is signed by both the buyer and seller of the allowances, but plans are underway to enable utilities to submit allowance transfers electronically with just the signature (or its electronic equivalent) of the seller. With just two staff members, USEPA processes most allowance transactions within one day of receipt.

\section{Lessons from the US Acid Rain Program}

From 1995 through 1997 the Acid Rain Program exceeded expectations, with firms over-achieving the reduction target at less than half the forecast cost. These results follow from the very flexible structure of the program, one component of which was the trading provision. In 1997 utilities exchanged 7.9 million allowances and purchased additional allowances through the annual auction. This total excludes intra-firm transfers. This activity represents a significant increase over prior years: 0.9 million allowances traded in 1994; 1.9 million in 1995; and 4.4 million in 1996. In searching for explanations for the relatively low level of initial activity, analysts have cited relatively high transaction costs at first, the behavior of public utility commissions, and legislation in some states that promoted the use of locally-produced coal (Burtraw, 1995).

The price of allowances has been far below initial forecasts, an issue that has attracted considerable attention. Prior to passage of the Clean Air Act Amendments of 1990 , industry estimates of abatement costs were $\$ 1,000$ per ton and USEPA forecast allowance prices were in the $\$ 750$ per ton range. As an ultimate backstop for compliance, the Congress authorized direct allowance sales by USEPA at a price of $\$ 1,500$ per ton. Lower than forecast allowance prices have several explanations. Prices for virtually every form of compliance are well below anticipated levels. The price of low-sulphur western coal delivered to mid-west and eastern markets has declined due to productivity improvements in extraction, and transport and deregulation of rail rates. Engineers have found ways to blend low-sulphur coal with high sulfur coal to meet emission limits. Innovations in the scrubber industry have reduced the cost of scrubbing by approximately 50 per cent. Many utilities committed themselves to scrubbers and other relatively expensive control measures based on early engineering cost studies. If they had better-anticipated $\mathrm{SO}_{2}$ control costs, utilities would have ordered fewer scrubbers. The consequence of greater than expected compliance cause a downward pressure on allowance prices in Phase I.

Analysts debate the role that allowance trading plays in stimulating costeffectiveness in $\mathrm{SO}_{2}$ control for coal-fired power plants. There is no doubt that $\mathrm{SO}_{2}$ control has experienced tremendous technological and productivity improvement over a very short period of time, leading to lower allowance prices than had been 
anticipated. The issue is the extent to which allowance trading is necessary to achieve these gains. Burtraw (1995) concluded that it is the flexible, performance-based design of the program that has stimulated the development of low cost compliance measures seen in Phase I, and that within that framework allowance trading played an incremental, positive role.

A recent USEPA assessment of the Acid Rain Program put the costs at \$1.2 billion annually in Phase I and \$2.2 billion annually in Phase II (USEPA, 1995). The same USEPA report estimated the mean value of annual health benefits at $\$ 10.6$ billion in Phase I and \$40 billion in Phase II. Interestingly, ecological benefits (fish and forests) were not a major reason for acid rain control legislation, yet health effects now appear to be the dominant benefit component. An independent assessment reached a similar conclusion - that benefits will be much greater than costs (Burtraw et al., 1998).

\section{Effluent Bubble}

In concept, an example of a water effluent bubble could be a facility with multiple discharge points wrapped in an imaginary bubble, with a facility-wide discharge limit rather than separate limits at the individual points of discharge. USEPA's implementation of the effluent bubble for the iron and steel industry was dictated by a 1983 settlement agreement among the USEPA, the Natural Resources Defense Council (NRDC), and the American Iron and Steel Institute. The agreement supports the use of bubbling under the Clean Water Act, but imposes constraints on the approach. Bubbling of effluents from iron and steel plants is acceptable provided that net reductions are achieved in total effluents. Relative to BAT (best available technology) limits that are in effect, bubbling must involve an average reduction of at least 15 per cent in the mass of suspended solids and 10 per cent in the mass of other pollutants.

Since the bubble became available to the industry, seven iron and steel plants in the mid-west have used the provision. Three of the mills no longer use the bubble-one facility closed down and two have changed ownership, a cause for termination of bubbling rights. The steel effluent bubble has produced some compliance cost savings for the industry but no innovations in pollution control.

\section{Point-point Effluent Trading}

Effluent trading dates to the early 1980s, when Wisconsin created a state-wide program to give sources such as wastewater treatment plants and pulp and paper mills added flexibility to meet state water quality 
standards through the trading of effluent rights.

Analysis showed that the potential from trading was significant: \$7 million annually or roughly one-half of anticipated compliance costs for biological oxygen demand (BOD) regulations (O'Neil, 1983). The program that was implemented allows trading rights to discharge wastes that increase BOD between point sources. Sources that control more than required under their discharge permit may sell those incremental rights to sources that control less than is required. Strict conditions are imposed on would-be buyers of rights: trading of rights is allowed only if the buyer is a new facility, is increasing production, or is unable to meet required discharge limits despite optimal operation of its treatment facilities. Traded rights must have a life of at least one year, but may not run past the expiry date of the seller's discharge permit, at most a five-year period. Since effluent discharge limits may change with each permit renewal, there can be no guarantee that rights that were traded in during one permit period would be available during subsequent permit periods.

The State initiated BOD trading programs on two rivers: a 35-mile stretch of the Fox River and 500 miles of the Wisconsin River. For administrative reasons, the Fox River was divided into three segments; the Wisconsin River, five segments. The Fox River program includes 21 parties: five mills and two towns in each of the three administrative segments. Twenty-six parties are included in the Wisconsin River program. To date, trading under these programs has been disappointing, involving a single trade on the Fox River between a municipal wastewater plant and a paper mill. One reason for the limited activity is that dischargers developed a variety of compliance alternatives not contemplated when the regulations were drafted. Second, there were and remain questions about the vulnerability of the program to legal challenge, since the Clean Water Act does not explicitly authorize trading and the standards set by the State do not conform fully to the national policy of uniformity established in the Act. Finally, as noted above, the State imposed severe restrictions on the ability of sources to trade.

\section{Point-nonpoint Effluent Trading}

Three programs allow the trading of nutrient discharges between point and nonpoint sources: Dillon Reservoir, Cherry Creek Reservoir, and the Tar-Pamlico 
Basin. These programs are discussed in turn.

Dillon Reservoir. Dillon Reservoir, which supplies Denver with more than one-half of its water supply, is situated in the midst of a popular recreational area. Four municipal wastewater treatment plants discharge into the reservoir: the Frisco Sanitation District, Copper Mountain, the Breckenridge Sanitation District, and the Snake River treatment plant of the Keystone area. Due to concerns that future population growth in the region could lead to eutrophic conditions in Dillon Reservoir, as well as the discovery that Copper Mountain was exceeding its discharge limits, USEPA launched a study of the Dillon Reservoir in 1982 under its Clean Lakes Program. The study indicated that phosphorus discharges would have to be reduced to maintain water quality and accommodate future growth. Point source controls alone were unlikely to be sufficient; runoff from lawns and streets and seepage from septic tanks also would have to be reduced.

Cherry Creek. Like the Dillon Reservoir, Cherry Creek Reservoir is also a source of water for the Denver region and an important recreation area. The Denver Regional Council of Governments established an effluent-trading program for Cherry
Creek very similar to that at Dillon. One difference is that trading at Cherry Creek has been nonexistent to date, reflecting the fact that phosphorus discharges at municipal wastewater treatment facilities remain below limits set by the Colorado Water Quality Commission.

Tar-Pamlico Basin. The North Carolina Environmental Management Commission designated the Tar-Pamlico Basin as nutrientsensitive waters in 1989 , in response to findings that algae blooms and low dissolved oxygen threatened fisheries in the estuary. North Carolina law requires that upon designating an area as nutrient sensitive, the Division of Environmental Management (DEM) must identify the nutrient sources, set nutrient limitation objectives, and develop a nutrient control plan.

\section{Wetland Mitigation Banking}

In recent years, as scientists
pointed out the ecological importance of wetlands, government policies at the federal, state, and local levels have come to emphasize wetland preservation, not development. Developers whose proposed actions would destroy wetlands are increasingly being forced to minimize damage to wetlands, and to offset what damage 
occurs through wetland protection or enhancement offsite. Sometimes the offset takes the form of compensation; that approach is described more fully in the section on fees, taxes and charges. This section describes wetland mitigation banking, a procedure for offsetting the adverse impacts of development on wetlands.

Wetland mitigation banks are created through a memorandum of understanding (MOU) among federal and state officials and a bank administrator. Generally the MOU would describe the responsibilities of each party, the physical boundaries of the bank, how mitigation credits will be calculated, and who is responsible for long-term management of the bank. Credits, which are usually denominated in terms of acres of habitat, may only be used to mitigate development within the same watershed. State regulations would cover issues such as where mitigation credits can be used (for example, statewide or within a watershed) and the compensation ratios that would be required for various types of development. Existing banks vary from a few acres to over 7,000 acres.

About 100 wetland mitigation banks in at least 15 states are currently in operation and many more are in advanced stages of planning. Wetland mitigation banking was featured in the 1996 Farm Bill as part of the Wetland Reserve Program. Wetland mitigation banking has been endorsed by USEPA, the Army Corps of Engineers (which oversees most development in wetlands under Section 404 of the Clean Water Act), and by the authors of leading legislative initiatives to reauthorize the Clean Water Act. All of these suggest that wetland mitigation banking will grow in importance as a means of protecting and enhancing the nation's wetlands.

\section{Wood Stove and Fireplace Permit Trading}

Telluride City tried to combat the problem through CAC regulations. In 1977 the city passed an ordinance limiting new residential construction to one stove or fireplace per unit. While this might have slowed the deterioration in air quality, continued new construction virtually guaranteed that air quality would continue to worsen, which it did into the 1980s. In 1987, the city adopted a program, part CAC and part modeled on air pollution offsets that would guarantee improvements in air quality. Existing wood stove and fireplace owners were grand fathered with operating permits, but required to meet stringent performance standards within 3 years: 6 grams of 
particulate matter and 200 grams of CO per hour. During the first two years of the program those individuals converting their fireplaces and wood stoves to natural gas could earn a rebate of $\$ 750$, partially defraying their costs. For new construction, no new permits would be issued for wood-burning stoves or fireplaces. To install such an appliance in new construction, the owner must produce permits to operate two fireplaces or stoves. The only place these permits could be acquired was from existing permit owners.

In a matter of months a lively market in second-hand permits developed, with potential buyers and sellers making contact through classified advertisements. By the mid-1990s transaction prices for permits were in the $\$ 2,000$ range. In the years after Telluride adopted the program, it has reported no violations of the ambient air quality standard for particulate matter. Other mountain communities in Colorado, Utah, and Montana with air pollution problems soon implemented similar programs to encourage the retirement of older inefficient fireplaces and wood stoves. The programs all aimed at reducing the burning of wood, but some offered no rebate for conversion to natural gas. From the available evidence, the programs appear to have been a success, achieving air quality goals quickly and at a relatively modest cost. A project for future research would compare and contrast the approaches taken by different communities, as well as assess the costs and effectiveness of the programs.

\section{Grass Burning Permit Trading}

The City of Spokane, Washington is nestled in the Spokane River basin about 400 feet below the surrounding Columbia River Plateau, forming a natural trap for air pollution during temperature inversions. The area exceeds the federal standard of 24-hour $\mathrm{PM}_{10}$ (particulate matters less than 10 microns in diameter) several times each year, due to a combination of unpaved roads, wind-blown dust, grass burning and wood stoves.

Grass burning had been subject to permit for years. The program superimposes on the permit process a countywide cap of 35,000 acres that may be burned each year. Growers are allocated permits to burn based on burning permits they held during the base period 1985 to 1989 . The overall cap does not appear to be binding; it exceeds the actual acreage burned every year since 1971. However, some grass growers found themselves short of desired permits because they had planted other crops during the base period or they had 
rented their land to tenants (who held the permits) during the base period. Parties submit sealed bids and offers prior to the auction. The party with the highest bid is matched with the party with the lowest offer, with the actual transaction occurring at a price midway between the bid and offer. If the quantity offered was not all purchased by that bidder, the bidder with the next lower price is then matched with the remaining offer. The process continues until all potential transactions are completed.

\section{Examples from Other Countries}

Under the terms of Germany's 1985 Federal Emission Control Law and 1986 Technical Instructions on Air Quality Control, new sources of air pollution can be established in areas with especially poor air quality, provided that pollution from nearby sources is lowered sufficiently to maintain air quality. This rule allows polluters to negotiate to determine who will reduce emissions and by how much. Under another scheme in effect until 1994, an existing facility could obtain a temporary exemption from tighter emissions abatement standards if it and nearby polluters achieved significant combined emission reductions.

Out of roughly 17,000 pollution abatement initiatives in Federal Environment Office statistics for
1991 and 1992, fewer than 50 involved offsets. According to the German Industries Association (BDI), the new source offset provisions, much like those for old sources, have involved almost exclusively intra-firm trading. The most common application appears to be the creation of a new source alongside an existing one that it will eventually replace. One recent interfirm initiative involved several fluoride-emitting ceramics factories concentrated in the Koblenz region. The factories sought to negotiate an arrangement under which only the larger ones would install abatement equipment while the smaller ones would help them pay for it. However, this initiative failed.

Under the Second Sulfur Protocol, trading of sulfur dioxide emissions among countries in northern Europe is theoretically possible. Under the protocol, trading ratios are referred to as "exchange rates." The procedures for approval of exchanges carry large administrative burdens and to date there have been no trades.

Canada's acid rain and chlorofluorocarbon (CFC) reduction programs make limited use of trading rights. The Province of Ontario's electric utility is allowed to trade emissions between its power stations, and the province allows trading 
between $\mathrm{SO}_{2}$ and $\mathrm{NO}_{\mathrm{X}}$ emissions. Inter-business trading is not allowed under this system. There has been little trading under these programs.

Poland experimented with tradable air pollution permits in the Chorzow area. According to an Eastern European study of incentives in environmental policy, this experiment "proved extremely successful in bringing visible improvements more rapidly and at a lower cost than attainable through traditional instruments". Lack of legal basis for tradable permits has prevented the use of such schemes elsewhere in the country. An environmental protection bill has been proposed including language that would provide a legal framework for trading schemes .

A 1993 revision of Taipei, China's Air Pollution Control Act included provisions under which individual sources may be exempted from emission standards if they can control sufficient amounts of the same types of emissions elsewhere in the same air pollution control region.

\section{Water Rights and Effluent Trading}

Three states in Australia take part in the Murray-Darling Basin Commission, which manages water resources for an area in which over half of Australia's agricultural output is produced. The basin system is naturally saline, with some stream inflows saltier than the sea. Extensive irrigation activities in the upstream states of New South Wales and Victoria, encouraged by the sale of irrigation water to farmers at low prices, increased the flow of salt into the river system, reducing water quantity and quality to the downstream state of South Australia. Irrigation activity in South Australia further added to salinity levels of the water before it reached downstream urban users.

Other examples of water rights trading may be cited. A limited amount of water rights trading takes places in the Central Valley of California. South Africa buys some of its water from Lesotho, Turkey from Bulgaria, and Singapore from Malaysia. Markets in water rights are of interest. Another example is that in April 1996, the Central Asian republics of Kyrgyzstan, Uzbekistan, and Kazakhstan announced an agreement intended to address the region's water and energy supply problems. Relying on hydroelectric power from the Syr Darya River for its heating needs, Kyrgyzstan stores water in spring and summer to have sufficient supply flowing through its hydroelectric dams in winter. Under the agreement, Kyrgyzstan will supply hydroelectricity and ensure 
sufficient flow of water through the Syr Darya River in return for gas from Uzbekistan and coal from Kazakhstan. While it is too early to assess the effectiveness of this trading scheme, it is patterned after historic water and energy transfers that took place when the entire region was centrally managed as part of the Soviet Union.

\section{International ET}

Much can be learned from experience in the establishment of international trading regimes, such as the 1987 Montreal Protocol on substances that deplete the ozone layer and the 1997 Kyoto Protocol to the United Nations Framework Convention on Climate Change. There has also been successful experience in domestic trading systems. Under the Acid Rain Program in the US, trading is cited to have stimulated cost-effectiveness in sulfur dioxide $\left(\mathrm{SO}_{2}\right)$ control for coalfired power plants. The flexible, performance-based design of the program stimulated the development of low cost compliance measures in 111 facilities. A second phase of the program is likely to see much greater reliance on allowance trading. This phase will involve 700 additional facilities, many of which are likely to select scrubbing as their method of compliance. Because more scrubbing would result in greater variation in the marginal costs of control across sources, there would be greater incentives to trade allowances.

\section{Prototype Carbon Fund}

Under the Kyoto Protocol,
reductions in $\mathrm{CO}_{2}$ that are demonstrated to be additional could be sold to partners in annex I countries (industrialized country grouping) through the Clean Development Mechanism (CDM). The capture of coalbed methane emissions could also provide energy sector opportunities for participation in CDM projects with annex I countries. However, additional information is needed to assess the cost-effectiveness of various activities. Also, methods must be developed to determine whether the investments would be additional to what would have been done under a baseline scenario. Means for monitoring must also be developed. A reliable third-party clearinghouse for available projects may facilitate participation by annex I countries. Developing countries could play an active role in each of these activities.

In January 2000, the World Bank launched the Prototype Carbon Fund (PCF) - the world's first market-based mechanism to address climate change and promote the transfer of finance and climate-friendly technology to developing countries. Governments 
have recognized the seriousness of the threat of climate change and during the 1990s negotiated the Framework Convention on Climate Change and the Kyoto Protocol. The protocol, which guides implementation of the Convention, includes specific emissions reduction targets for industrialized countries. It also contains provisions allowing them some flexibility so they can meet these commitments to reduce emissions in the most cost-effective manner.

According to the World Bank there are many opportunities to reduce emissions of greenhouse gases in developing countries at a cost of between $\$ 5$ and $\$ 15$ dollars a ton of carbon. This compares with a marginal abatement cost of upwards of $\$ 50$ a ton of carbon in advanced economies. It is the difference in cost to industrialized and developing countries of reducing greenhouse gas emissions that provides the opportunity for mutually beneficial trading relationships. The World Bank can negotiate prices for emissions reductions at about $\$ 20$ a ton of carbon ( $\$ 5$ a ton of $\left.\mathrm{CO}_{2}\right)$, thus covering the regulatory and market risks to contributors while providing adequate incentives to project sponsors and their governments in developing countries.
During the next three years, the World Bank will invest all the Fund's capital in 20 or so projects. Most are expected to be linked to projects identified by the World Bank Group as part of its regular work, but they can also originate from the private sector, other multilateral development banks, and bilateral donors. The primary focus will be on renewable energy technologies - such as wind, small hydro, and biomass energy technology - that would not be profitable without revenue from emissions reductions sold to the PCF. In some cases the PCF will finance such projects through local carbon funds modeled on the PCF but using financing from local commercial and development banks, as well as private companies. Some 20 countries have already declared interest in hosting PCF projects.

\section{Conclusion}

The continuing evolution of the application of ET shows that the direction it will take in the future is not yet clearly established. Change occurs as different models are implemented and evaluated. If the emphasis will be on CDM, a thorough review of past Joint Implementation Projects should be undertaken to identify lessons learnt. If the focus is to be on domestic 
trading of selected emissions, then capacity building and further pilot trading should be pursued. The promotion of ET for environmental management is consistent with the broad development strategies adopted by many developing countries in protecting the environment. In this context, governments could (i) provide policy support through studies that assess experiences in ET and identify the positive and negative aspects of implementation, (ii) promote more pilot trading systems, (iii) assist in capacity building in terms of training programs, human resource development, and institutional strengthening, and (iv) promote regional cooperation by exploring potential for CDM and related activities of various international protocols.

\section{Acknowledgement}

The authors wish to acknowledge the ADB's generosity for allowing them to freely use the materials presented in Emission Trading in the Energy Sector: Opportunities for the PRC, Energy Division (East), ADB, 1999. They also express their gratitude to Dr. Robert Anderson and anonymous reviewers for their contribution to this paper, although any remaining errors are their responsibility.

\section{References}

ADB (1997). Electric Utilities Data Book. Manila, Asian Development Bank.

Atkeson, E. (1997). Joint Implementation: Lessons From Title IV's Voluntary Compliance Programs. Working Paper 97-003, MIT Centre for Energy and Environmental Policy Research.

Butraw, D., K. Allan, M. Erin, A. David and F. Deirdre (1998). Costs and Benefits of Reducing Air Pollutants Related to Acid Rain. Contemporary Economic Policy, XVI: 379-400.

Burtraw, D. (1995). Cost Savings Sans Allowance Trades? Evaluating the $\mathrm{SO}_{2}$ Emissions Trading Program to Date. Resources for the Future. Discussion Paper 95-30, Washington, D.C.

Cason, T. (1995). An Experimental Investigation of Seller Incentives in EPA's Emissions Trading Auction. American Economic Review, 85: 9051022. 
Coase, R. (1960). The Problem of Social Cost. Journal of Law and Economics, 3: 1-44.

Ellerman, A.D., S. Richard, J. Paul, P.M. Juan and B. Elizabeth (1997). Emissions Trading under the US Acid Rain Program. MIT Centre For Energy and Environmental Policy Research.

Foster, V. and H. Robert (1995). Designing More Efficient Markets: Lessons from Los Angeles Smog Control. The Journal of Law and Economics, XXXVIII: 19-31.

Hausker, K. (1992). The Politics and Economics of Auction Design in the Market for Sulphur Dioxide Pollution. Journal of Policy Analysis and Management, 11: 553-572.

ICF Resources Incorporated (1989). Economic Analysis of Title IV (Acid Rain Provisions) of the Administration's Proposed Clean Air Act Amendments. H.R.3030/S.1490, Washington D.C.

Joskow, P.L., S. Richard and M.B. Elizabeth (1998). The Market for Sulfur Dioxide Emissions. American Economic Review, 88: 669-685.
Margulis, S. (1994). The Use of Economic Instruments in Environmental Policies: The Experiences of Brazil, Mexico, Chile and Argentina. Applying Economic Instruments to Environmental Policies in OECD and Dynamic NonMember Economies.

O'Conner, D. (1994). Managing the Environment with Rapid Industrialisation: Lessons from the East Asian Development Experience. OECD Development Centre.

O'Neil, W. (1983). Transferable Discharge Permits Trading under Varying Stream Conditions: A Simulation of Multiperiod Permit Market Performance on the Fox River, Wisconsin. Water Resources Research. 19: 608-612.

Portney, P. (1990). Economics and the Clean Air Act. Journal of Economic Perspectives, 4: 173-181.

South Coast Air Quality Management District (1992). Regional Clean Air Incentives Market. Diamond Bar, California.

USEPA (1995). Human Health Benefits from Sulphate 
Reductions under Title IV of the 1990 Clean Air Act Amendments. Office of Air and Radiation, Washington, D.C.

USEPA (1997). Finding of Significant Contribution and Rulemaking for Certain States in the Ozone Transport Assessment Group for Purpose of Reducing Regional
Transport of Ozone: Proposed Rule. 62FR216: 60317-60367.

USEPA (1998). Supplemental Notice for the Finding of Significant Contribution and Rulemaking for Certain States in the Ozone Transport Assessment Group for Purpose of Reducing Regional Transport of Ozone. 63FR90: 25901-25994. 